\title{
Impact of the Rural Clinical School of Western Australia on work location of medical graduates
}

\section{Denese E Playford \\ Associate Professor, Medical Education \\ Sharon F Evans PhD, AStat, Associate Professo Biostatistics \\ David N Atkinson MB BS, MPH Professor \\ Kirsten A Auret MB BS, FRACP Professor $^{3}$ \\ Geoffrey J Riley AM, FRANZCP, FRACGP, Winthrop Professo and Head \\ 1 Rural Clinical School of Western Australia University of Western Australia Perth, WA \\ 2 Rural Clinical School of Western Australia University of \\ Western Australia \\ Broome, WA. \\ 3 Rural Clinical School of Western Australia, University of \\ Western Australia, Albany, WA. \\ Denese.Playford@ rcswa.edu.au}

MJA 2014; 200: 104-107 doi: 10.5694/mjal3.11082

Online first 27/01/14 $\mathrm{n}$ the face of severe and ongoing medical workforce shortages in rural Australia, initiatives have been introduced to improve recruitment and retention in rural practice. ${ }^{1}$ These have included pathways for international medical graduates to enter the rural workforce, incentives for existing rural doctors, ruralbonded medical school places, quarantined rural student places in medical schools, scholarships for rural medical students, and undergraduate immersion in rural medicine through rural clinical schools (RCSs). The RCSs were intended to influence the future career choices of medical students and so contribute to a selfsustaining locally trained workforce.

It is clear in the international literature that multiple factors are associated with medical graduates' career destinations. A prospective longitudinal study of medical graduates followed up 30 years after they graduated showed that selecting rural-origin undergraduates with a declared interest in primary care and providing rural-immersion programs each independently and linearly increased graduates' likelihood of working rurally. ${ }^{2,3}$ Rural immersion has been favoured by some programs in the United States. ${ }^{4,5}$

Based on this collective evidence, the Australian Government initiated RCSs in 2002, with a mandate to produce rural doctors. Participating universities are financially supported to train $25 \%$ of medical graduates for at least 1 academic year in a rural setting.

Early Australian data showed that RCS exposure increases graduates' stated intention to work rurally. ${ }^{6}$ RCS graduates are also more likely than their peers to work rurally as prevocational doctors, ${ }^{7,8}$ and studies of small numbers of RCS graduates have found they are more likely to work in rural areas and to have a preference for primary care. ${ }^{9,10}$ However, longerterm outcomes for large numbers of RCS graduates have yet to be reported.

\begin{abstract}
Objective: To determine whether completing a year of the Rural Clinical School of Western Australia (RCSWA) program is associated with entering the rural medical workforce.

Design and setting: Cohort study of graduates from the University of Western Australia who completed Year 5 of medical school between 2002 and 2009, comparing work location (identified from the Australian Health Practitioner Regulation Agency database in March-June 2013) between those who participated in the RCSWA (RCSWA graduates) and those who did not (controls).
\end{abstract}

Main outcome measure: Rural or urban work location of graduates.

Results: Of 1116 eligible graduates, 1017 (91.1\%) could be traced and were included in the study. Of 258 RCSWA graduates, 42 (16.3\%) were working rurally compared with 36 of 759 controls (4.7\%). Of 195 RCSWA graduates from urban backgrounds, 29 (14.9\%) were working rurally compared with 26 of 691 urbanbackground controls (3.8\%). Of 63 rural-background RCSWA graduates, $13(20.6 \%)$ were working rurally, compared with 10 of 68 rural-background controls (14.7\%). Using logistic regression, RCSWA participation had a strong relationship with working rurally (rural-background RCSWA graduates: odds ratio [OR], 7.5; 95\% Cl, 3.5-15.8; urban-background RCSWA graduates: OR, 5.1; 95\% Cl, 2.9-9.1). Rural background without RCSWA participation (OR, 4.2; 95\% $\mathrm{Cl}, 1.8-9.2$ ) and older age (age in 2012, 30-39 years: OR, 2.2; 95\% Cl, 1.3-3.7 v $\geqslant 40$ years: OR, 6.6; $95 \% \mathrm{Cl}, 2.8-15.0$ ) were also significant factors for working rurally.

Conclusions: Participation in the RCSWA is strongly associated with greater likelihood of working rurally. Graduates from urban backgrounds who participated in the RCSWA were much more likely to work in rural areas than those who did not. These data substantiate the RCSWA as an effective rural workforce strategy.

Here, we report the impact of participation in the Rural Clinical School of Western Australia (RCSWA) on graduates' rural work relative to their non-RCSWA peers. Our hypothesis was that RCSWA participation is associated with increased rural work.

\section{Methods}

The RCSWA commenced at the University of Western Australia (UWA) in 2002, and expanded in 2007 to include the University of Notre Dame Australia medical school at Fremantle. The RCSWA is based at 13 sites across rural and remote WA. Participation in the RCSWA is based on application and an interview that selects those students most informed about the RCSWA and living independently.

For this study, the cohort comprised medical graduates from UWA who completed their fifth year between 2002 and 2009 and graduated by 2010 . This ensured graduates were in at least their third postgraduate year at the time of data collection in 2013. Medical students from the University of Notre Dame Australia were not included. RCSWA graduates were defined as those who undertook a fifth-year rural placement. The control group comprised graduates who had not participated in an RCSWA placement. The study was approved by the UWA Human Research Ethics Committee.

Students recruited into the UWA medical school through a quarantined rural pathway were identified as having a rural background. At the time, this was defined as having lived in a rural area of WA (towns $>75 \mathrm{~km}$ from the Perth central business district, all of which are classified as rural by the Australian Standard Geographical Classification - Remoteness Areas $\left[\right.$ ASGC-RA] ${ }^{11}$ ) for a minimum of 2 years and having completed Year 12 at a rural secondary school. All other students were classified as having an urban background. The few students 
who may have come from a rural background but did not enter through the rural pathway were included in the urban-background group.

Between March and June 2013, we accessed information in the Australian Health Practitioner Regulation Agency (AHPRA) database to identify graduates' work locations. Graduates were designated as working rurally if their primary practice location was in an area defined by the ASGC-RA as RA2-5, and urban if RA1. Graduates with an urban practice address were conservatively considered to be working in an urban location, even though many will have spent part of their year working on rural rotation. A previous comparison of the more detailed RCSWA work location database with AHPRA information showed at least $89 \%$ agreement. $^{12}$

Univariate comparisons were made using the $\chi^{2}$ test for categorical variables and the Kruskal-Wallis test for age, as this showed marked kurtosis and a tail towards the upper range. We used logistic regression to analyse predictors of the probability of working rurally by maximum likelihood estimation. Factors of current age, sex, rural background and RCSWA participation were considered. All interactions between covariates were included, but only interactions between rural background and RCSWA participation remained significant and were included in the final model. Further logistic regressions were run within the RCSWA cohort to identify the effect of covariates independently of RCSWA participation. Analyses were also run within the rural-background group, to identify any independent effect of RCSWA participation. All analyses were conducted using SAS version 9.3 (SAS Institute).

\section{Results}

We identified 1187 graduate doctors who had completed Year 5 between 2002 and 2009 (Box 1). After excluding those who had not been eligible for the RCSWA or were working overseas, 1116 graduates were eligible for inclusion in the study. Of these, 99 could not be traced (three RCSWA graduates and 96 controls), leaving 1017 graduates (91.1\%) who were included in the study. The 96 control

\section{Description of University of Western Australia medical graduates}

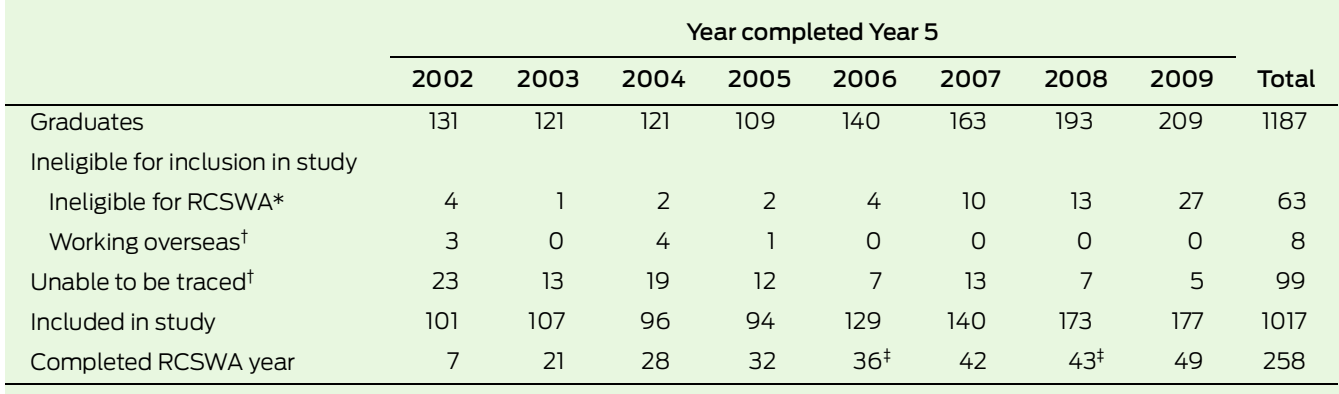

RCSWA $=$ Rural Clinical School of Western Australia. $*$ Temporary residents and those with student visas. $\dagger$ From information in the Australian Health Practitioner Regulation Agency (AHPRA) database, accessed March-June 2013. ‡Excludes two RCSWA graduates in 2006 and one in 2008 who were unable to be located in the AHPRA database. graduates not found on the AHPRA database were not statistically different from other controls by rural background, sex and age.

Of the 1017 graduates, 258 (25.4\%) had participated in the RCSWA and $759(74.6 \%)$ were controls. The RCSWA graduates differed from the control group in that more RCSWA graduates were from rural backgrounds, female and younger (Box 2).

Of the 258 RCSWA graduates, 42 $(16.3 \%)$ were working as rural doctors, compared with 36 of the 759 controls (4.7\%) $(P=0.001) \quad($ Box 3). Overall, there was no significant association between the proportion of graduates working rurally and the year in which they completed Year 5 of medical school. However, smaller proportions of graduates who had completed Year 5 in the 2 most recent years had a rural work address.

Univariate analyses found significant associations between rural work and RCSWA participation, rural background, sex and older age ( $\geqslant 40$ years) (Box 4). Further analysis showed that $16.7 \%$ (15/90) of those who were aged over 35 years at enrolment in Year 5 were working rurally, compared with
$6.8 \%(63 / 927)$ of their younger classmates $(P=0.003)$.

RCSWA graduates from an urban background were working as rural doctors at a similar rate as those from a rural background who did not participate in the RCSWA (Box 5). There may have been some additional benefit of the RCSWA program for graduates from a rural background, but this was based on small numbers and was not statistically significant $(P=0.28)$.

The RCSWA was oversubscribed from 2006 onwards by a total of 67 UWA graduates. Unsuccessful RCSWA applicants were not significantly different from successful applicants in terms of sex, age or rural background. However, only five unsuccessful applicants (7.5\%) had a rural work address, significantly less than the RCSWA graduates for this period $(P=0.04)$.

In the final logistic regression model, the combination of having a rural background and participating in the RCSWA was the strongest predictor of being a rural doctor (odds ratio [OR], 7.5; 95\% CI, 3.5-15.8), followed by RCSWA participation without a rural background (OR, 5.1;

\section{Demographic characteristics of RCSWA and control University of Western Australia graduates}

\begin{tabular}{|c|c|c|c|c|}
\hline & RCSWA graduates $(n=258)$ & Control graduates $(n=759)$ & Total $(n=1017)$ & $P$ \\
\hline Working rurally* & $42(16.3 \%)$ & $36(4.7 \%)$ & $78(7.7 \%)$ & 0.001 \\
\hline Female & $162(62.8 \%)$ & $380(50.1 \%)$ & $542(53.3 \%)$ & 0.004 \\
\hline Rural background & $63(24.4 \%)$ & $68(9.0 \%)$ & $131(12.9 \%)$ & 0.001 \\
\hline Median age in 2012 (IQR) & $29.0(27.7-31.2)$ & $30.0(27.6-32.1)$ & $29.7(27.6-31.9)$ & $0.007^{\dagger}$ \\
\hline Age group & & & & 0.006 \\
\hline$<30$ years & $157(60.9 \%)$ & $381(50.2 \%)$ & $538(52.9 \%)$ & \\
\hline 30-39 years & $94(36.4 \%)$ & $336(44.3 \%)$ & $430(42.3 \%)$ & \\
\hline$\geqslant 40$ years & $7(2.7 \%)$ & $42(5.5 \%)$ & 49 (4.8\%) & \\
\hline
\end{tabular}

RCSWA = Rural Clinical School of Western Australia. IQR = interquartile range. * Defined as RA2-5 in the Australian Standard Geographical Classification - Remoteness Areas. ${ }^{11} \dagger$ Based on a Kruskal-Wallis test because the age distribution showed marked kurtosis and a tail towards the upper range. Age was recoded into 10-year groups for further analysis. 
3 Work location* of RCSWA and control University of Western Australia graduates

\begin{tabular}{|c|c|c|c|c|}
\hline \multirow[b]{2}{*}{$\begin{array}{l}\text { Year completed } \\
\text { Year } 5\end{array}$} & \multicolumn{2}{|c|}{ RCSWA graduates $(n=258)$} & \multicolumn{2}{|c|}{ Control graduates $(n=759)$} \\
\hline & $\begin{array}{c}\text { Rural work } \\
\text { location }^{\dagger}\end{array}$ & $\begin{array}{c}\text { Urban work } \\
\text { location }^{\ddagger}\end{array}$ & $\begin{array}{l}\text { Rural work } \\
\text { location }^{\dagger}\end{array}$ & $\begin{array}{l}\text { Urban work } \\
\text { location }^{\ddagger}\end{array}$ \\
\hline 2002 & $2(28.6 \%)$ & $5(71.4 \%)$ & $7(7.4 \%)$ & $87(92.6 \%)$ \\
\hline 2003 & $4(19.0 \%)$ & $17(81.0 \%)$ & $5(5.8 \%)$ & $81(94.2 \%)$ \\
\hline 2004 & $4(14.3 \%)$ & $24(85.7 \%)$ & $6(8.8 \%)$ & $62(91.2 \%)$ \\
\hline 2005 & $4(12.5 \%)$ & $28(87.5 \%)$ & $1(1.6 \%)$ & $61(98.4 \%)$ \\
\hline 2006 & $8(22.2 \%)$ & $28(77.8 \%)$ & $4(4.3 \%)$ & $89(95.7 \%)$ \\
\hline 2007 & $12(28.6 \%)$ & $30(71.4 \%)$ & $3(3.1 \%)$ & 95 (96.9\%) \\
\hline 2008 & $5(11.6 \%)$ & $38(88.4 \%)$ & $6(4.6 \%)$ & $124(95.4 \%)$ \\
\hline 2009 & $3(6.1 \%)$ & $46(93.9 \%)$ & $4(3.1 \%)$ & 124 (96.9\%) \\
\hline Total & $42(16.3 \%)$ & $216(83.7 \%)$ & $36(4.7 \%)$ & $723(95.3 \%)$ \\
\hline
\end{tabular}

RCSWA = Rural Clinical School of Western Australia. * From information in the Australian Health Practitioner Regulation Agency database, accessed March-June 2013. † Defined as RA2-5 in the Australian Standard Geographical Classification - Remoteness Areas (ASGC-RA)." $¥$ Defined as RA1 in the ASGC-RA." background without RCSWA participation (OR, 4.2; 95\% CI, 1.8-9.2) was also significant, as was older age (3039 years: OR, 2.2; 95\% CI, $1.3-3.7 \mathrm{v}$ $\geqslant 40$ years: OR, 6.6; $95 \% \mathrm{CI}, 2.8-$ 15.0). Women remained more likely to work rurally $(\mathrm{OR}, 1.6$; 95\% CI, 0.92.6), but this was no longer statistically significant.

Further analyses within the group of RCSWA graduates showed that the major factors associated with rural work were age $\geqslant 40$ years (OR, 17.0; 95\% CI, 3.3-130.1) and being female (OR, 2.6; 95\% CI, 1.2-6.3). Rural background was not independently significant (OR, 1.4; 95\% CI, 0.6-2.9).

Within the smaller group of 131 rural-background doctors, no covariate was significantly associated with rural work. However, both older age ( $\geqslant 40$ years, OR, 4.1; 95\% CI, 0.917.3) and RCSWA participation (OR,

1.8; 95\% CI, 0.7-4.9) may have important effects.

\section{Discussion} increase intention to practise rurally, clear increase in the number of gradusustained across all RCS programs, will make a significant contribution to Australian rural medical workforce shortages. $^{13}$ Community Curriculum (PRCC) prolikely to be in rural work relative to
95\% CI, 2.9-9.1) (Box 6). A rural

While RCS programs are known to we found that substantial proportions of RCSWA graduates actually do return to rural areas to practise. The ates practising rurally in this study, if

This finding corroborates results of previous smaller studies. Graduates of the Flinders University Parallel Rural gram were overwhelmingly more non-PRCC graduates. ${ }^{9}$ In this small cohort of 29 doctors contacted 5 years

\begin{tabular}{|c|c|c|c|}
\hline & Number (\%) & Odds ratio $(95 \% \mathrm{Cl})$ & $P$ \\
\hline \multicolumn{4}{|l|}{ RCSWA } \\
\hline Yes & 42/258 (16.3\%) & $3.91(2.44-6.25)$ & 0.001 \\
\hline No & $36 / 759(4.7 \%)$ & 1.0 & \\
\hline \multicolumn{4}{|c|}{ Rural background } \\
\hline Yes & 23/131 (17.6\%) & $3.22(1.87-5.39)$ & 0.001 \\
\hline No & $55 / 886(6.2 \%)$ & 1.0 & \\
\hline \multicolumn{4}{|l|}{ Sex } \\
\hline Female & $51 / 542(9.4 \%)$ & $1.72(1.07-2.83)$ & 0.03 \\
\hline Male & $27 / 475$ (5.7\%) & 1.0 & \\
\hline \multicolumn{4}{|l|}{ Age group } \\
\hline$<30$ years & $30 / 538$ (5.6\%) & 1.0 & 0.002 \\
\hline 30-39 years & $37 / 430(8.6 \%)$ & $1.59(0.97-2.64)$ & \\
\hline$\geqslant 40$ years & $11 / 49(22.5 \%)$ & $4.90(2.20-10.3)$ & \\
\hline
\end{tabular}

after graduation, there was a strong preference for primary care, similar to findings in the North American literature. ${ }^{3}$ In a study with more detail but also with small numbers, University of Queensland RCS graduates have shown similar positive rural return and preference for primary care. ${ }^{10}$

We also found that medical graduates from urban backgrounds who undertook an RCSWA year were nearly four times more likely to be working rurally up to 10 years after graduation than those not exposed to the RCSWA. The observed outcome for urban-background RCSWA graduates was as strong as that for rural background alone. It is similar to the previously documented positive effect of rural background on medical graduates' future rural practice. ${ }^{14}$ This result is significant, given the limited pool of rural-background students available to be recruited into medicine. Our study demonstrates that some of the substantially larger pool of future medical students from urban backgrounds can also, with appropriate experience, be convinced to pursue a rural career. Qualitative research could explore which aspects of the RCSWA experience are associated with future rural practice.

Our study methods were conservative and are likely to have underestimated rural work, especially for more recent graduates. The finding that fewer graduates from the 2 most recent years had a rural work address is likely related to the limited number of fullyear positions available in rural WA for junior doctors. WA has relatively small rural population centres and most junior doctors who work rurally do so on rotation from urban centres. Our unpublished, detailed follow-up of RCSWA graduates documents that many are still in training programs undertaking brief placements in rural areas. These short rural placements are less likely to result in a change of primary practice address on the AHPRA database and hence will not be included as rural work in this analysis. ${ }^{12}$

Although all cross-sectional study designs have the potential weakness of sampling bias, overall sampling bias is unlikely in this study as we had data on $91 \%$ of graduates. Our finding that untraceable controls did not differ from other controls further decreases this likelihood. However, the small 
sample size of rural-background students who participated in the RCSWA and collinearity between rural background and RCSWA participation meant that statistically significant relationships could not be established. Larger numbers are required to better investigate the possible associations between rural background and rural practice. It would be worthwhile to increase the sampling of rural-background RCS students by including graduates from all RCSs and medical schools in Australia.

It can be argued that RCSWA graduates already had rural practice intentions as medical students and may have practised rurally anyway. However, it has been widely documented that urban-background graduates only become rural doctors in small

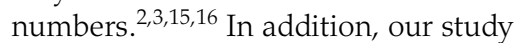
shows that students who applied for but did not attend the RCSWA were not working rurally in significantly increased numbers. The size of the observed difference on urban-background graduates who participated in the RCSWA suggests an impact that is substantially greater than just initial intention or positivity towards rural practice.

The proportion of RCSWA graduates who returned to rural practice in this study compares well with results from a 30-year-old program in the US, which has a threefold higher return for its selective rural program relative to standard-intake graduates. ${ }^{17}$ It also compares well with results from several retrospective studies for rural general practitioners having had rural undergraduate experiences (OR range, $2.0-3.7){ }^{15,16,18,19}$

We add to the literature with our finding that women and older graduates are more likely to enter rural work after RCS exposure. Women were initially recruited into the RCSWA in higher numbers and, contrary to findings about mature male practitioners already in rural practice, ${ }^{19}$ female RCSWA graduates were more likely to enter rural practice, although this did not quite reach statistical significance in our multivariate model. In a field that has been maledominated, this is a very positive result. Our finding that older entrants were more likely to work rurally is in line with results from the Flinders
University PRCC program. 9 The increasing numbers of graduate medical programs in Australia may well be good for future rural workforce.

This study is an important addition to the evidence for RCS success in contributing to the Australian rural medical workforce. It provides strong support for the Australian Government to maintain the program and to increase RCS funding to expand the number of places. This would allow increased rural recruitment from the large pool of urban-background medical students. Given the expense of using locums and fly-in fly-out workers to overcome rural workforce shortages, state and territory governments should add to RCS capacity by investing targeted additional funding to increase RCS-based training in sites of greatest workforce shortage. Our finding that the RCS program is producing a new rural workforce indicates this would be well placed.

Competing interests: No relevant disclosures.

Received 19 Aug 2013, accepted 26 Nov 2013.

1 Joyce C, Wolfe R. Geographic distribution of the Australian primary health workforce in 1996 and 2001. Aust N Z J Public Health 2005; 29: 129-135.

2 Rabinowitz HK, Diamond JJ, Markham FW, Santana AJ. The relationship between entering medical students' backgrounds and career plans and their rural practice outcomes three decades later. Acad Med 2012; 87: 493-497.

3 Rabinowitz HK, Diamond JJ, Markham FW, Wortman JR. Medical school programs to increase the rural physician supply: a systematic review and projected impact of widespread replication. Acad Med 2008; 83: 235-243.

4 Ramsey PG, Coombs JB, Hunt DD, et al. From concept to culture: the WWAMI program at the University of Washington School of Medicine.Acad Med 2001; 76: 765-775.

5 Zink T, Center B, Finstad D, et al. Efforts to graduate more primary care physicians and physicians who will practice in rural areas: examining outcomes from the University of Minnesota-Duluth and the Rural Physician Associate Program. Acad Med 2010; 85: 599-604.

6 Eley DS, Baker PG. Will Australian rural clinical schools be an effective workforce strategy? Early indications of their positive effect on intern choice and rural career interest. Med J Aust 2007; 187: 166167.

7 McDonnel Smedts A, Lowe MP. Efficiency of clinical training at the Northern Territory Clinical School: placement length and rate or return for internship. Med J Aust 2008; 189: 166-168.

8 Playford DE, Denz-Penhey H, Skinner L, Murdoch JC. Will Australian rural clinical schools be an effective workforce strategy? Early indications of their positive effect on intern choice and rural career interest [letter]. Med J Aust 2008; 188: 190.

9 Worley P, Martin A, Prideaux D, et al. Vocational career paths of graduate entry medical students at Flinders University: a comparison of rural, remote and tertiary tracks. Med J Aust 2008; 188: 177-178.

10 Eley DS, Synnott R, Baker PG, Chater AB. A decade of Australian Rural Clinical School graduates where are they and why? Rural Remote Health 2012; 12: 1937.
5 University of Western Australia graduates participating in the RCSWA and/or having a rural background

\begin{tabular}{llcc}
$\begin{array}{l}\text { RCSWA } \\
\text { participation }\end{array}$ & $\begin{array}{l}\text { Rural } \\
\text { background* }\end{array}$ & Total & $\begin{array}{c}\text { Working } \\
\text { rurally }\end{array}$ \\
\hline No & No & 691 & $26(3.8 \%)$ \\
No & Yes & 68 & $10(14.7 \%)$ \\
Yes & No & 195 & $29(14.9 \%)$ \\
Yes & Yes & 63 & $13(20.6 \%)$ \\
\hline
\end{tabular}

RCSWA = Rural Clinical School of Western Australia. * Defined as living in a rural area of WA for at least 2 years and having completed Year 12 at a rural secondary school.

\section{Final logistic regression model for working in a rural location*}

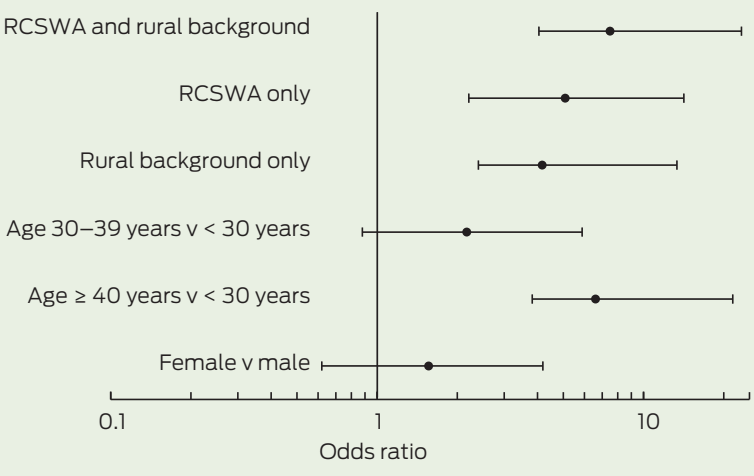

RCSWA = Rural Clinical School of Western Australia. * Log scale. Bars represent $95 \%$ confidence intervals.

11 Australian Government Department of Health. Australian Standard Geographical Classification Remoteness Area (ASGC-RA). http://www.health gov.au/internet/otd/Publishing.nsf/Content/RAintro (accessed Dec 2013).

12 Playford D, Power P, Boothroyd A, et al. Is the National Registration website (Australian Health Practitioner Regulation Agency) effective in tracking Australian medical graduates' rural work? Aust J Rural Health 2013; 21: 249-253.

13 Deloitte Access Economics. Review of the rural medical workforce distribution programs and policies. Canberra: Department of Health and Ageing, 2011.

14 Laven G, Wilkinson D. Rural doctors and rural backgrounds: how strong is the evidence? A systematic review. Aust J Rural Health 2003; 11: 277-284.

15 Carter RG. The relation between personal charateristics of physicians and practice location in Manitoba. CMAJ 1987; 136: 366-368.

16 Wilkinson D, Laven G, Pratt N, Beilby J. Impact of undergraduate and postgraduate rural training, and medical school entry criteria on rural practice among Australian general practitioners: national study of 2414 doctors. Med Educ 2003; 37: 809814.

17 Rabinowitz HK, Diamond JJ, Markham FW, Hazelwood CE. A program to increase the number of family physicians in rural and underserved areas: impact after 22 years. JAMA 1999; 281: 255260.

18 Rourke JT, Incitti F, Rourke LL, Kennard M. Relationship between practice location of Ontario family physicians and their rural background or amount of rural medical education experience. Can J Rural Med 2005; 10 : 231-240.

19 Laven GA, Beilby JJ, Wilkinson D, McElroy HJ. Factors associated with rural practice among Australian-trained general practitioners. Med J Aust 2003; 179: 75-79. 